\title{
Problemáticas en la separación desde la teoría de los fenómenos transicionales en niño con diagnóstico de trastorno de ansiedad por separación*1
}

\author{
Karin Borgeaud C.*2 \\ Daniela Fernández S.*3 \\ Paz Valenzuela S. ${ }^{* 4}$
}

\begin{abstract}
Esta investigación comprende un estudio de caso único, por lo tanto, no pretende dar una explicación generalizable. Sin embargo, contribuye como caso ejemplar que puede evocar en el lector otros casos clínicos con similitudes y, al mismo tiempo, ilustrar desarrollos teóricos difundidos. La presente investigación, supone la existencia de una relación entre las problemáticas en la separación y la experiencia de lo transicional en la díada y contribuye a la comprensión de esta relación desde la teoría de los fenómenos transicionales de Winnicott.
\end{abstract}

Palabras claves: Ansiedad de separación, angustia de separación, fenómenos transicionales, objeto transicional

\footnotetext{
*1 Basado en Tesis para optar al grado de Magister en Clínica Psicoanalítica con Niños y Jóvenes en Universidad Alberto Hurtado, titulada: Problemáticas en la Separación desde la Teoría de los Fenómenos Transicionales en Niño con Diagnóstico de Trastorno de Ansiedad por Separación que recibe Atención Psiquiátrica en Complejo Asistencial Barros Luco, Santiago-Chile 2016.

*2 Complejo Asistencial Barros Luco (Santiago, Chile).

*3 Universidad Viña del Mar (Viña del Mar, Chile).

${ }^{*}$ Universidad Diego Portales (Santiago, Chile).
} 
ARTIGOS

\section{Introducción}

Las problemáticas en torno a la separación entre padres e hijos, así como también sobre la pérdida del objeto amado, han sido desarrolladas desde diferentes perspectivas teóricas debido al impacto de éstas en la vida y en el desarrollo del niño involucrado.

Desde la perspectiva psiquiátrica, el individuo en desarrollo puede presentar un Trastorno de Ansiedad por Separación (TAS), una manifestación psicopatológica correspondiente a los trastornos de ansiedad más comunes en la infancia. El TAS está definido en el Manual Estadístico de los Trastornos Mentales (DSM-IV) como "la ansiedad excesiva e inapropiada para la etapa del desarrollo del niño en relación a la separación de éste de sus figuras de apego" (Pacheco, 2009). En Chile la prevalencia total de TAS en la población infantojuvenil es 4,8\% (De La Barra, Vicente, Saldivia, \& Melipillán, 2012).

$\mathrm{Si}$ bien, el concepto TAS es de uso psiquiátrico, y no es homologable con la "angustia de separación" descrita en la literatura psicoanalítica, ambos hacen mención a las dificultades propias de la separación. Desde esa convergencia, se plantea establecer un diálogo entre ambas disciplinas que permita enriquecer y ampliar la comprensión psiquiátrica del TAS desde la mirada psicoanalítica, en particular desde la teoría de los fenómenos transicionales de Winnicott.

Los objetos transicionales (OT) tienen un rol en la elaboración de los sentimientos de pérdida frente a la separación, también evocan a la madre. Son objetos libidinales, mediadores simbólicos que evocan a la madre, sin confundirse con ella, ayudando al bebé a sostener una espera y una soledad para que no resulte demasiado angustiosa (Winnicott, 1959-2009).

Rev. Latinoam. Psicopat. Fund., São Paulo, 20(2), 294-306, jun. 2017 


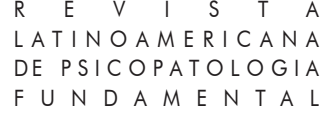

Durante sus primeros años, el niño puede recurrir a objetos $\mathrm{y} / \mathrm{o}$ fenómenos, denominados como objetos transicionales (OT) y/o fenómenos transicionales (FT) que están investidos por las características de sus cuidadores principales y que hacen más tolerable esta angustia de separación que suele atemperarse cuando los niños empiezan a entender que los padres siguen existiendo aunque ellos no puedan verlos, y que van a volver más tarde (Villanueva \& Sanz, 2009). Es a partir de las conceptualizaciones de Winnicott (1971-2003) sobre el "área de ilusión", donde se desenvuelven los procesos designados como "fenómenos transicionales" (FT) que sería posible plantear la existencia de una relación entre éstos y las problemáticas de la separación.

Esta investigación supone la existencia de una relación entre las problemáticas en la separación y la experiencia de lo transicional en la díada y comprende un estudio de caso único, por lo tanto, no pretende dar explicación generalizable. Sin embargo, contribuye como caso ejemplar que puede evocar en el lector otros casos clínicos con similitudes y, al mismo tiempo, ilustrar desarrollos teóricos difundidos.

Por esto, se enmarca dentro de un carácter empírico-clínico, recurriendo

296 a la metodología del estudio de caso. Bajo esto se seleccionó el caso de un niño que estuviera en edad escolar, que consultará por primera vez a un servicio público de Psiquiatría infantil, que cumpliese criterios diagnósticos para TAS y que junto a dos de sus cuidadores estuviese dispuesto a participar en la investigación. Se realizaron entrevistas en profundidad a los padres y al niño, a este último ademásse le pidieron dibujos para que los contenidos surgieran en la medida que la relación transferencial lo permitiese.

En los aspectos éticos se ha respetado la privacidad y el anonimato de las personas involucradas y se contó con la aprobación del comité de ética de la institución donde fue realizado el trabajo.

\section{El caso de Pedro}

Pedro tiene ocho años y es llevado por su madre a un servicio de Psiquiatría Infantil de un centro asistencial público, debido a meses de ausentismo escolar, cuando debiese cursar $2^{\circ}$ año de Enseñanza Básica.

Sobre su historia familiar, ambos padres (Antonia y Norman) tienen un pololeo breve en la adolescencia, años después tienen un reencuentro amoroso único del que surge Pedro. La madre se entera del embarazo al mes de su 


\section{ARTIGOS}

concepción y mantiene oculta la identidad del progenitor hasta avanzado el embarazo, al quinto mes devela la identidad a su familia y estos la incitan a comunicarle al padre su estado, y desde ahí padre y madre inician una relación de pareja formal.

Al nacer el menor, vive con la madre y la familia de origen de ésta, el padre es vecino del sector y mantiene una regularidad diaria en el contacto, a los dos años de vida del menor los padres inician una convivencia independiente de sus hogares de orígenes que dura un año, con la separación de los padres, la madre y el menor vuelven al hogar de origen materno, el padre se queda habitando dos años en el hogar que habitó la familia nuclear y luego vuelve a su hogar de origen, en el vecindario de su hijo.

La familia de origen materno está compuesta por la abuela materna quien tuvo un primer matrimonio del que nacen sus cuatro hijas mayores, la abuela se separa en un contexto de violencia intrafamiliar y alcoholismo del esposo, posterior a la separación las hijas no vuelven a tener contacto regular con su padre ni tampoco reciben apoyo económico de parte de éste. Posteriormente, la abuela tiene una relación casual con un vecino del sector y surge el embarazo de Antonia, la relación se termina cuando ella es una recién nacida y no se establece una relación padre e hija. Destaca, que las cuatro hermanas de la madre son madres solteras y han tenido embarazos adolescentes.

La familia de origen paterno está compuesta por el matrimonio de los abuelos, tienen tres hijos, el padre es el hijo del medio y en su hogar también vive la hermana menor de éste y su sobrino.

Como hitos importantes se destaca que el menor al año de vida empieza a asistir a sala cuna y desde entonces se hace evidente su rechazo a asistir a las instituciones de este carácter, cuando él tiene dos años de vida la madre inicia una jornada laboral muy extensa, siendo la abuela paterna quien ejerce el cuidado los días lunes a viernes y los padres conviven con él solo los fines de semana, sistema que se mantiene hasta los 3-4 años de vida. Luego pasa a vivir diariamente con la madre y la abuela paterna lo cuida mientras dura la jornada laboral de la madre, hasta los cinco años de vida en que esta función la pasa a ocupar la abuela materna.

Posterior a la separación de los padres, la madre inicia una relación lésbica por dos años y abre con su familia su homosexualidad, pero no con Pedro. Esta relación amorosa termina a fines del año 2014 y desde entonces se encuentra soltera. Por su parte, el padre lleva más de dos años en una relación heterosexual sin convivencia. 


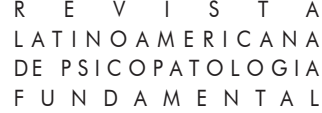

El análisis de los resultados fue sistematizado, a la luz de la propuesta teórica de Winnicott, según los siguientes ejes temáticos:

1. "Madre suficientemente buena" implica que en todos los casos los cimientos de la salud mental debe ponerlos la madre (Winnicott 1950/1991). Para poder hacerlo en el grado necesario, la madre necesita estar protegida de la realidad externa, de modo de poder gozar de un período de preocupación (materna primaria), siendo el bebé el objeto de su preocupación (Winnicott 1950/1991).

La madre, dotada de las experiencias de sus medias hermanas, y de su propia madre, podía también prescindir de un padre para su hijo y también de la ayuda de los otros en los cuidados de Pedro recién nacido. En las primeras entrevistas a ésta, se pone en evidencia su deseo de ser madre, pero en este deseo el tercero es prescindible, no es relevante.

Podemos suponer que la lectura que hace Antonia, de las necesidades que tiene Pedro, resulta vaga, inconsistente y en ocasiones distorsionada. Esto puede explicarse, por los antecedentes históricos de Antonia, quién ha experimentado diversos tipos de negligencia y abuso en su vida; y, además, de una relación con el padre de Pedro marcada por el conflicto de quién puede ejercer mejor la paternidad, que en vez de ser un soporte en conjunto, causa una enemistad y desmerecer constante para con el quehacer del otro.

La lactancia es un aspecto muy particular de la relación primitiva madre-bebé: Pedro presentó una alergia a la proteína de leche de vaca, prolongando la lactancia materna hasta los dos años de vida.Afortunada o desafortunadamente, como dice la madre, Pedro hace síntomas de una alergia alimentaria que conllevan un retraso en la re-inserción laboral de la madre, y también en una incorporación más tardía y dificultosa de otros alimentos que no sean el de origen materno. Es una primera señal de que la separación y la introducción de lo exógeno a la díada van a ser resistidos.

2. El lugar del padre

Constituye una serie de experiencias necesarias para salir de la relación dual, que abren camino a lo nuevo, que rompe el encierro de la repetición, abriendo en el bebé, camino hacia la terceridad.

En la observación personal del trabajo con niños es posible testimoniar el hecho de que en numerosos discursos maternos hay una extrema abolición del tercero, donde la madre siente a ese hijo como propiedad exclusiva, como creación propia, en un discurso cerrado, especular, simétrico a su deseo fusional. En el caso de Antonia, su posición es llamativamente oscilante, predominando la devaluación de lo paterno.Antonia, vacila a lo largo de 


\section{ARTIGOS}

las entrevistas contradictoriamente entre darle y no darle valor a la función paterna. Dicho valor está puesto sobre todo en la potencialidad del rol de proveedor económico del padre, sin embargo, en ella también aparece la fantasía de que puede ser mejor prescindir por completo de lo masculino.

A su vez, la posición del padre es oscilante, lo reclama y lo deja de vuelta con la madre, no logra rescatarlo de esta hiperinvestidura.

\section{El espacio transicional en la diada}

Se les denomina precursores de los objetos transicionales, a aquellos que aunque tienen la capacidad de consolar al niño, no han sido descubiertos o inventados por él, de hecho pulgar y chupete, son los precursores más comunes (Gaddini, 1997). El chupete de Pedro es un típico precursor y que, por lo tanto, tiene poco que ver con el OT propiamente dicho, ni en su realidad ni en su valor simbólico, siendo la propiedad tranquilizadora de ambos la única cosa común.

Anzieu (2003; citado en Guerra, 2007), plantea la importancia de la prohibición del tocar, como una forma de manifestación del "No", que condiciona la renuncia al primado de los placeres de la piel y la transformación de la experiencia táctil en representaciones básicas, terreno del pensamiento. La ausencia de la prohibición del tocar entre Antonia y Pedro, no promueve la diferenciación del yo-piel con un yo-psíquico.

La adquisición de la transicionalidad, depende de la confiabilidad de la madre. Antonia, va asociando recuerdos de su propia infancia y se encuentra con las fallas de sus padres, de esta manera va ilustrando la falta de confiabilidad de éstos, pero pocas veces se detiene en reflexionar sobre cómo estás mismas fallas se van repitiendo en su relación con Pedro. En el relato de Antonia abundan polaridades sin integrar, relato que ilustra lo paradójico y poco previsible de sus conductas y decisiones.

4. El paso de la vigilia al dormir

Para dormirse a solas, Guerra (2005) ha identificado como condición el tolerar ese momento de vacío, de "nadificación" de la noche, primero el bebé tiene que poder vivenciar en el día ciertas experiencias de espera, de cierto vacío en la relación con la madre. Además de esto, es relevante la actitud materna de tolerar la soledad y el silencio interactivo, así ella y el bebé pueden "habitar" espacios psíquicos separados.

A sus ocho años, Pedro no ha sido interdicto en la posibilidad de tocar los pezones de su madre, abuela y padre. A lo largo de los años sí ha diferenciado el cuerpo de éstos, quienes son sus más cercanos, del resto, pero aún pareciese necesitar la concretud corporal de sus seres más significativos 


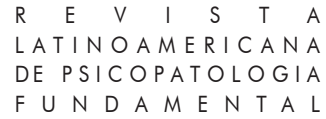

para alcanzar un confort al que no tiene acceso en base a las representaciones mentales de estos. No se establece "la interdicción del tocar", y el papel del padre comotercero se desdibuja y las experiencias de terceridad se ven muy limitadas (Guerra, 2005). Esto determina una fuerte dependencia y una intensa angustia de separación, que en el día se conduce bajo la forma de un vínculo tiránico en el que el niño va construyendo una relación excesivamente simétrica, de igual a igual con su madre.

Otro elemento a considerar, es la orientación sexual de la madre, si bien ella ha tenido parejas lésbicas, estas relaciones se han dado fuera del hogar, y no habiéndose las comunicado verbalmente a Pedro. No se introduce un tercero en la relación, la madre aparenta frente a Pedro una falta de vida sexual adulta y se fomenta la fantasía de completud entre ambos que se grafica en el dormir adherido al seno materno, negando su propio conflicto sexual.

5. ¿Es posible la separación?

En el dibujo de Pedro de la figura humana (dibujo 1), destaca la imposibilidad de dibujarse así mismo por separado de su madre, ilustración que refleja su estado de adhesión a ésta. En su dibujarse evidencia lo más regresivo e inhibido de él, es como si se minimizara hasta invisibilizar la diferencia entre él y la madre.

\section{Dibujo 1}

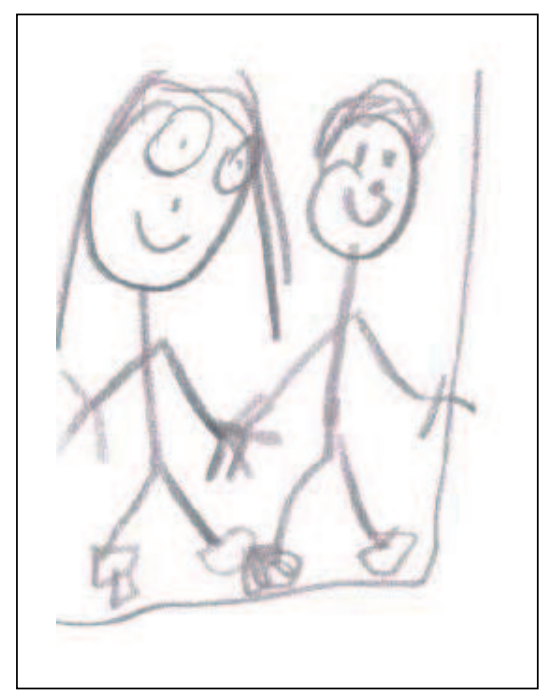

Rev. Latinoam. Psicopat. Fund., São Paulo, 20 (2), 294-306, jun. 2017 


\section{ARTIGOS}

Los FT se sitúan en la raíz de la aptitud del individuo para emplear símbolos, los círculos más amplios de contacto social de alguna manera representan o simbolizan el cuidado de la madre. Pero, cuando no hay un progenitor que otorgue la capacidad de metaforización, el empleo de los símbolos y la introyección de un ambiente sostenedor se verán comprometidos junto a la capacidad de separarse.

Son numerosas las separaciones a las que ha estado expuesto Pedro, a su vez éstas han sido abruptas y no fueron atemperadas, al contrario, interrumpieron de manera violenta en su historia. Sin madre confiable internalizada y donde ronda de manera persistente la amenaza del abandono, cabe preguntarse cómo podría Pedro desarrollar la capacidad de estar solo, y sin ésta, cómo podría separarse para ir al colegio.

La angustia, aun con diferentes conceptualizaciones es abordada por cada teoría desde el peculiar punto de vista del autor, esto permite descubrir que en cierto sentido se está hablando de lo mismo y a la vez de algo diferente.La capacidad de contener la angustia, en particular la angustia de separación, varía de un individuo a otro, y lo que se denomina "normalidad" corresponde a la capacidad de enfrentar la angustia y elaborarla psíquicamente (Quinodoz, 1993).

6. El lenguaje y la entrada al mundo social

La escuela, lugar de sociabilización obligatoria, puede ser una nueva oportunidad para la complejización del psiquismo, pues se incrementan las oportunidades para ampliar su potencial simbólico.

Antonia tiene dificultades en asumir la responsabilidad de ir poniendo límites a los deseos de Pedro y en encausarlo y/o inscribirlo en la legalidad de la institución escolar.A su vez, Norman pareciese tener menos dificultades en este ámbito, pero su irrupción en instalar la ley es vivida tanto por Pedro, según su propio relato en las entrevistas, y por Antonia de manera muy violenta. En consideración a esto, Antonia oscila entre convocarlo y excluirlo de los cuidados de Pedro, y Norman también oscila entre atribuirse autoridad sobre el cuidado de su hijo o no. 


\section{Conclusiones y discusión}

El desarrollo de la investigación realizada, contribuye a una enriquecida comprensión de las dificultades en la separación de Pedro, en relación a la experiencia de lo transicional en la díada.

En síntesis, de este análisis, se destaca la relación entre un niño sin fallas en las identificaciones primarias, con un fort-da (Freud, 1920/2008) constituido, pero frágil, que transita entre separarse y no, con marcadas dificultades para tolerar la separación que despierta en él intenso sufrimiento psíquico. Con una madre que fue capaz de entrar en el estado de "preocupación materna primaria", pero que ha sido sustentadora de forma ambivalente, y que oscila entre la polaridad de saber todo respecto al maternaje hasta prescindir de la ayuda del otro y entre dudar masivamente de su quehacer materno hasta declararse incompetente. Así, también, oscila entre ejercer de forma exclusiva y excluyente el cuidado de su hijo y entre delegar el total cuidado al otro inhabilitándose en su quehacer, no pudiendo ejercer un maternaje con el otro.

Esta actitud materna ambivalente es crucial en reforzar el miedo a la pérdida de la figura materna, siendo esto un elemento fundamental en la dificultad de Pedro de separarse, que es, a su vez, una dificultad de la madre. Una función materna ambivalente que se relaciona con los esbozos de la capacidad de simbolización de Pedro. Espacio transicional, espacio por excelencia de la simbolización, donde se trata de sostener una tambaleante representación mental de los cuidados maternos que en su caso no logran atemperar la ausencia materna.

El separarse es también una dificultad de la madre, de esta manera parece ser que impide el cuestionamiento de su sexualidad.

A modo de discusión, resulta necesario destacar que la investigación fue llevada a cabo por investigador único, esto conlleva a limitaciones en la obtención de datos, que sin duda, no abarca otros antecedentes que pudiesen ser relevantes o de interés, así como dimensiones no abordadas. En cuanto a las implicancias, este tipo de estudio posibilita llevar a la clínica aspectos teóricos y desde ahí enriquecer el quehacer del clínico.Quienes trabajan en el ámbito de la salud mental enfrentan problemas similares, y el diálogo entre los distintos abordajes sin duda contribuye a tener más recursos para abordarlos. 


\section{ARTIGOS}

\section{Referências}

Association, American Psychiatric. (1995). Manual Diagnóstico y Estadístico de los Trastornos Mentales IV (DSM IV). Barcelona: Masson.

De la Barra, F., Vicente, B., Saldivia, S., \& Melipillán, R. (2012). Estudio de epidemiología psiquiátrica en niños y adolescentes en Chile. Estado actual. Med. Clin. Condes , 23(5), 521-529.

Freud, S. (2008). Más allá del principio de placer, Psicología de las masas y análisis del yo y otras obras. In Sigmund Freud Obras Completas (Vol. XVIII). Buenos Aires: Amorrortu. (Trabajo original publicado en 1920).

Gaddini, R. (1997). Formación de objeto e ideas fijas. Psicoanálisis APdeBA, XIX (3), 355-369.

Guerra, V. (2007). Papel de la triadificación-terceridad en el proceso de separación durante el primer año de vida. Revista de la APPIA (16).

Guerra, V. (2005). Trastornos de sueño en bebes: la noche, las pesadillas y lo siniestro en el psiquismo parental. (Inédito).

Pacheco B, V. T. (2009). Trastorno de ansiedad por separación. Revista chilena de pediatría, 80(2), 109-119.

Quinodoz, J. M. (1993). La soledad domesticada. (J. Etcheverry, Trad.). Buenos Aires: Amorrortu.

Villanueva, C., \& Sanz, L. (2009). Ansiedad de separación: delimitación conceptual, manifestaciones clínicas y estrategias de intervención. Revista Pediatría de Atención Primaria, 11(43), 457-469.

Winnicott, D. (1991). Ideas y definiciones. In Exploraciones Psicoanaliticas, 1. Buenos Aires: Paidós. (Trabajo original publicado en 1950).

Winnicott, D. (1992). La capacidad para estar solo. In Los procesos de maduración y el ambiente facilitador (pp. 36-46). Buenos Aires: Paidós. (Trabajo original publicado en 1958).

Winnicott, D. (2003). Realidad y Juego (10ª Reimpresión). (F. M. Trad.) Barcelona: Gedisa. (Trabajo original publicado en 1971).

Winnicott, D. (2009). El destino del objeto transicional. In Exploraciones psicoanalíticas I (L. Wolfson, Trad.; $5^{\text {a }}$ Reimpresión, pp. 72-78). Buenos Aires: Paidós. (Trabajo original publicado en 1959). 


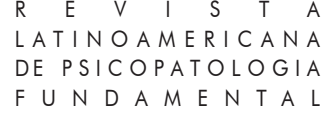

\section{Resumos}

(Problemáticas na separação a partir da teoria dos fenômenos transicionais em uma criança com diagnóstico de transtorno de ansiedade por separação)

Esta pesquisa é de um estudo de caso único. Portanto, não pretende dar uma explicação generalizada. Contribui, porém, como um caso exemplar que pode estimular a memória dos leitores que tenham casos similares, e também, ao mesmo tempo, ajuda a ilustrar o desenvolvimento teórico. Esta pesquisa demonstra a relação entre os problemas da separação e a experiência dessa relação no dia a dia e contribui para a compreensão dessa relação a partir da teoria dos fenômenos transicionais de Winnicott.

Palavras-chave: Ansiedade de separação, angústia na separação, fenômeno transicional, objeto transicional.

(Separation difficulties analyzed in the light of the transitional phenomena theory in a child diagnosed with separation anxiety disorder)

This research is based on a unique case report, therefore it does not intend to provide a generalizable explanation, but it contributes with an exemplary case that could stimulate readers to remember similar cases, also helping to illustrate the theoretical development. This research shows the relation between separation difficulties and the transitional experience in the maternal-infant relationship, and contributes to the comprehension of this relationship based on Winnicott's transitional phenomena theory.

Key words: Separation anxiety, separation angst, transitional phenomena, transitional object

(Problèmes de séparation analysés selon la théorie des phénomènes transitionnels chez un enfant diagnostiqué d'anxiété de séparation)

Cet article présente une étude de cas unique et n'a donc pas l'intention de fournir une explication généralisée. Cependant, il représente un cas exemplaire qui pourrait évoquer chez le lecteur d'autres cas cliniques similaires et il permet, à la fois, d'illustrer le développement de théories existantes. Cette étude décrit le rapport entre les problèmes de séparation et l'expérience de ce rapport dans la vie quotidienne. Il contribue d'ailleurs à la compréhension de ce rapport à partir de la théorie des phénomènes transitionnels de Winnicott.

Mots clés: Anxiété de séparation, angoisse de séparation, phénomène de transition, objet transitionnel

(Analyse von Trennungsproblemen aufgrund der Theorie der Übergangsphänomene in einem Kind, dass mit Trennungsangst diagnostiziert wurde)

Dieser Artikel analysiert eine Einzelfallstudie und dessen Schlussfolgerungen können daher nicht verallgemeinert werden. Ziel ist es, eine Parallele zu ähnlichen 


\section{ARTIGOS}

Fällen zu ziehen und seine theoretische Entwicklung zu beschreiben. Der Artikel beschreibt das Verhältnis zwischen Trennungsschwierigkeiten und die Erfahrung dieser Beziehung im Alltag. Er trägt somit zum Verständnis dieser Beziehung bei, basierend auf Winnicotts Theorie der Übergangsphänomene.

Schlüsselwörter: Trennungsangst, Furcht bei Trennung, Übergangsphänomen, Übergangsobjekt

（过渡现象理论中的孩子分离困难问题与分离焦虑症状的诊断）

本论文来源于一个独特的病例报告, 因此本论文的结论不能广泛普及。但 是本病例可以激发读者对其它类似病例的回忆，同时有助于诠释理论的发展。 这项研究展示在母婴关系中, 分离困难与过渡经验之间的关系并有助于利用 Winnicott's过渡现象理论来理解这种关系。

关键词：分离焦虑，分离困难，过渡现象，短暂目标。

Citação/Citation: Borgeaud C., K., Fernández O. D. \& Valenzuela, P. (2017, junho). Dificultades en la separación desde la teoría de los fenómenos transicionales en niño con diagnóstico de trastorno de ansiedad por separación. Revista Latinoamericana de Psicopatologia Fundamental, 20(2), 294-306. http://dx.doi.org/10.1590/1415-4714.2017v20n2p294.6

Editores do artigo/Editors: Profa. Dra. Ana Maria Rudge e Profa. Dra. Sonia Leite

Recebido/Received: 9.6.2016/ 6.9.2016 Aceito/Accepted: 15.8.2016 / 8.15.2016

Copyright: (C) 2009 Associação Universitária de Pesquisa em Psicopatologia Fundamental/ University Association for Research in Fundamental Psychopathology. Este é um artigo de livre acesso, que permite uso irrestrito, distribuição e reprodução em qualquer meio, desde que o autor e a fonte sejam citados / This is an open-access article, which permits unrestricted use, distribution, and reproduction in any medium, provided the original authors and sources are credited.

Financiamento/Funding: Os autores declaram não ter sido financiados ou apoiados / The authors have no support or funding to report.

Conflito de interesses/Conflict of interest: Os autores declaram que não há conflito de interesses / The authors have no conflict of interest to declare. 


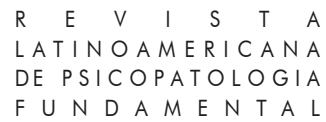

Karin Borgeaud C.

Médico Psiquiatra Infantil y del Adolescente.

Complejo Asistencial Barros Luco

Gran Avenida José Miguel Carrera 3204

Santiago, Chile.

Código Postal: 8900085

dra.borgeaud@gmail.com

\section{Daniela Fernández O.}

Psicóloga; Docente Universidad Viña del Mar (Viña del Mar, Chile).

Escuela de Ciencias Jurídicas y Sociales

Los Fresnos 91, Miraflores,

Viña del Mar, Chile

Código Postal 2561091

daniela.paz.f@gmail.com

\section{Paz Valenzuela S.}

Psicóloga; Docente Universidad Diego Portales.

El Trovador 4280

Oficina 204 - Las Condes

Santiago, Chile

$306 \quad$ Cód. Postal 7550075

paz.valenzuela@udp.cl

This is an open-access article, which permits unrestricted use, distribution, the original authors and sources are credited. 